\title{
O significado de desmedicalização da assistência ao parto no hospital: análise da concepção de enfermeiras obstétricas
}

THE MEANING OF UNMEDICALIZATION OF CHILDBIRTHATTENDANCE IN HOSPITALS: AN ANALYSIS OF THE OBSTETRIC NURSES' CONCEPTION

\author{
EL SIGNIFICADO DE LA DESMEDICALIZACIÓN DE LAASISTENCIA DEL PARTO EN EL HOSPITAL: \\ ANÁLISIS DE LA CONCEPCIÓN DE ENFERMERAS-PARTERAS
}

\author{
Octavio Muniz da Costa Vargens ${ }^{1}$, Jane Márcia Progianti ${ }^{2}$, Anna Carolina Ferreira da Silveira ${ }^{3}$
}

\begin{abstract}
RESUMO
Este estudo teve como objetivo o processo de construção do significado de desmedicalização para enfermeiras obstétricas. Trata-se de pesquisa qualitativa baseada nos princípios da Grounded Theory. Os dados foram obtidos e analisados entre fevereiro e abril de 2006. Foram entrevistadas oito enfermeiras obstétricas atuantes no ensino, pesquisa e/ou assistência ao parto, que adotam a proposta desmedicalizadora como orientação da sua prática. A análise dos dados levou à construção de quatro categorias: refletindo sobre sua prática, caracterizando a prática obstétrica hospitalar como medicalizada, incomodando-se com a assistência medicalizada e identificando os princípios da desmedicalização, cuja integração permitiu identificar o processo construindo o significado de desmedicalização. 0 respeito à Fisiologia, bem como não usar desnecessariamente práticas intervencionistas como rotina constituíram princípios da desmedicalização. A reflexão sobre sua vida e a caracterização da prática obstétrica hospitalar, como medicalizada, fizeram parte do processo mental das enfermeiras na desconstrução das habilidades adquiridas no modelo biomédico.
\end{abstract}

\section{DESCRITORES}

Enfermagem obstétrica.

Parto.

Saúde da mulher.

\begin{abstract}
This study was aimed at analyzing the process through which nurse-midwives have given meaning to unmedicalized attention. It is a qualitative study based on the Grounded Theory. Data were obtained and analyzed between February and April of 2006. Eight nurse-midwives who adopt the unmedicalized approach as orientation in their practice were interviewed. Through the analysis of the data it was possible to identify four categories - thinking about her practice; characterizing as medicalized the obstetric practice in hospitals; feeling annoyed by medicalized attendance; and identifying the principles of unmedicalization -, whose integration made possible to identify the process of building the meaning of unmedicalization. Respect to Physiology, as well as not to use unnecessarily interventionist practices as routine, constituted principles of unmedicalization. The reflection about their lives and the characterization of the obstetric practice in hospitals as medicalized were part of the nurses' mental process to revert the construction of the abilities acquired in the biomedical model.
\end{abstract}

\section{KEY WORDS}

Obstetrical nursing.

Parturition.

Women's health.

\section{RESUMEN}

En este estudio se tuvo como objetivo el proceso de construcción del significado de la desmedicalización para enfermeras obstétricas. Se trata de una investigación cualitativa basada en los principios de la Grounded Theory. Los datos fueron obtenidos y analizados entre febrero y abril del 2006. Se entrevistaron a ocho enfermeras obstétricas actuantes en la enseñanza, investigación y/o asistencia del parto, que adoptan la propuesta desmedicalizadora como orientación de su práctica. El análisis de los datos llevó a la construcción de cuatro categorías: reflexionando sobre su práctica, caracterizando la práctica obstétrica hospitalaria como medicalizada, incomodándose con la asistencia medicalizada e identificando los principios de la desmedicalización cuya integración permitió identificar el proceso construyendo el significado de desmedicalización. El respeto a la Fisiología, así como el no uso innecesario de prácticas intervencionistas como rutina constituyeron principios de la desmedicalización. La reflexión sobre su vida y la caracterización de la práctica obstétrica hospitalaria, como medicalizada, formaron parte del proceso mental de las enfermeras en la desconstrucción de las habilidades adquiridas en el modelo biomédico.

\section{DESCRIPTORES \\ Enfermería obstétrica. \\ Parto. \\ Salud de las mujeres.} ${ }^{1}$ Enfermeiro Obstetra; Doutor; Professor Titular do Departamento de Enfermagem Materno-Infantil da Faculdade de Enfermagem da Universidade Estadual
do Rio de Janeiro (UERJ); Líder do Núcleo de Estudos e Pesquisas Enfermagem, Mulher, Saúde e Sociedade (NEPEN-MUSAS). Rio de Janeiro, RJ, Brasil.
omcvargens@uol.com.br ${ }^{2}$ Enfermeira Obstétrica; Doutora; Professora Adjunta do Departamento de Enfermagem Materno-Infantil da Faculdade de
Enfermagem da UERJ; Vice-líder do Núcleo de Estudos e Pesquisas Enfermagem, Mulher, Saúde e Sociedade (NEPEN-MUSAS). Rio de Janeiro, RJ, Brasil.
jmprogi@uol.com.br ${ }^{3}$ Enfermeira contratada do Hospital Universitário Pedro Ernesto/UERJ, residente de enfermagem do Curso de Especialização em
Enfermagem Obstétrica da Faculdade de Enfermagem UERJ/SMS-RJ. Rio de Janeiro, RJ, Brasil. annacarolfs@yahoo.com.br 


\section{INTRODUÇÃO}

Observando o campo obstétrico hospitalar no Brasil nos deparamos com diferentes realidades assistenciais, das quais destacamos duas. Em uma, verificamos a dor do corpo e da mente femininos expressos nos olhares e nos corpos das mulheres que foram submetidas a procedimentos, que de longe procuraram, trazer algum tipo de conforto e respeito à sua saúde. Noutra, observamos um atendimento às mulheres, oposto ao descrito, que prima pelo respeito e conforto e que não se restringe apenas ao trabalho de parto.

Estas realidades podem ser encontradas em Instituições hospitalares distintas ou podem co-existir numa mesma Instituição. 0 que estabelece a diferença são as atitudes dos profissionais no cotidiano das relações do campo obstétrico hospitalar. Estas atitudes vão ao encontro das disposições que cada um incorporou durante sua formação e durante seu contato com os modelos institucionais. Dependendo das concepções das disposições incorporadas, os profissionais geram habilidades diferenciadas ${ }^{(1)}$.

Assim, muitos profissionais são adeptos do cuidado medicalizado e freqüentemente fazem uso de intervenções no cuidado ao parto. Outros, como é o caso das enfermeiras, superaram este modelo de assistência e desenvolvem habilidades não invasivas que são peculiares do modelo humanizado feminino e desmedicalizado de assistência ao parto.

No contexto atual, a enfermeira obstétrica é a única profissional não médica que tem sido associada com um saber/fazer que vem ao encontro da possibilidade de resgatar 0 parto fisiológico como um fenômeno feminino onde a mulher seja a protagonista ${ }^{(2)}$. Deste modo, esta profissional vem contribuindo para a consolidação do modelo humanizado de assistência ao parto que necessariamente passa pelo cuidado desmedicalizado(3).

A humanização do parto e nascimento foi adotada pelo Ministério da Saúde, como política pública de atenção à saúde da mulher, no final dos anos 90 . Esta se deu através publicação de um conjunto de portarias iniciadas em 1998, que instituiu o Programa de Humanização do PréNatal e Nascimento(4). Desde então a desmedicalização ganhou diferentes sentidos e significados para os diversos profissionais.

Entendemos que desmedicalizar não significa a simples exclusão do profissional ou de práticas médicas da assistência, mas eliminar o raciocínio clínico-médico como única alternativa para entender a parturição. Significa ao mesmo tempo apresentar às mulheres outras opções de cuidado, tendo em mente que diferentes opções e estratégias podem e devem conviver como direito de escolha da mulher ${ }^{(5)}$.
Em função do exposto, objetivamos analisar o processo de construção do significado de desmedicalização da assistência ao parto hospitalar para a enfermeira obstétrica. A realização deste estudo se justifica pela importância de colocar em evidência o significado de desmedicalização que está norteando a prática da enfermagem obstétrica hospitalar, do ensino e da pesquisa. Acreditamos também que representa importante contribuição para que atitudes desmedicalizadas sejam adotadas pelos profissionais que tem a responsabilidade de implementar esta política de humanização, fortalecendo-a no contexto nacional.

\section{MÉTODO}

Trata-se de estudo qualitativo com base nos princípios da Grounded Theory. Este método consiste no desenvolvimento de modelos teóricos a partir da análise comparativa constante de dados ${ }^{(6-7)}$. Por esse método o pesquisador precisará compreender, pela perspectiva do sujeito, suas ações pelo que ele entende e diz de si e de outros, respeitando seu mundo e as interpretações que ele faz nessas interações, compartilhando suas definições ${ }^{(6-7)}$.

Os sujeitos pesquisados foram oito enfermeiras obstétricas que atuam no ensino, na pesquisa e/ou na assistência ao parto e que adotam a proposta da desmedicalização como orientação da sua prática.

A inclusão dos mesmos no estudo se deu de acordo com o processo de amostragem teórica ${ }^{(6-7)}$, de modo que o primeiro grupo foi composto por três enfermeiras com atuação na assistência ao parto em instituições públicas da rede municipal do Rio de Janeiro. A análise destas entrevistas indicou a necessidade de buscar informações adicionais junto a enfermeiras que atuassem na docência. Assim sendo o segundo grupo amostral constituiu-se de três enfermeiras sendo duas atuantes apenas na docência e uma atuante na docência e na assistência. A análise comparativa destas seis entrevistas indicou a inclusão de enfermeiras, no grupo, que tivessem atuação também como pesquisadoras. Deste modo foram incluídas como terceiro grupo amostral duas enfermeiras docentes com atuação na pesquisa e ensino de pós-graduação.

Os dados foram obtidos através de entrevistas semiestruturadas a partir de roteiro pré-determinado. Para a realização das entrevistas foram realizados contatos prévios que aconteceram pessoalmente, por telefone e/ ou email, solicitando a participação do sujeito. A entrevista foi efetuada em um ambiente combinado com o participante, desde que o mesmo se sentisse à vontade para falar e expor suas opiniões. Os dados foram obtidos e analisados no período de Fevereiro a Abril de 2006. 
Em atendimento ao disposto na Resolução no 196/ 96 do Conselho Nacional de Saúde que dispõe sobre normas e procedimentos éticos em pesquisas envolvendo seres humanos, o estudo foi submetido e aprovado pelo Comitê de Ética em Pesquisa do HUPE/UERJ (1379-CEP/ HOPE/2006), sendo que todas as participantes foram devidamente esclarecidas sobre a pesquisa e assinaram Termo de Consentimento Livre e Esclarecido.

0 processo de análise dos dados aconteceu em três etapas. A primeira constou da transcrição das entrevistas com a subseqüente distribuição vertical e seqüencial dos discursos, o que permitiu o procedimento da codificação aberta ou substantiva ${ }^{(6)}$. A segunda consistiu do agrupamento de códigos afins, dando origem à categorização provisória ${ }^{(6-7)}$. A terceira etapa consistiu na codificação teórica( ${ }^{(6)}$, com a qual emergiram as categorias e seus respectivos componentes (subcategorias), cuja análise comparativa e integração permitiram descrição e explicação do processo de construção do significado de desmedicalização para enfermeiras obstétricas.

\section{RESULTADOS}

A análise dos dados levou à construção de quatro categorias principais: refletindo sobre sua prática, caracterizando a prática obstétrica hospitalar como medicalizada, incomodando-se com a assistência medicalizada, e, identificando os princípios da desmedicalização.

Estas categorias são apresentadas a seguir juntamente com as suas respectivas subcategorias.

\section{Refletindo sobre a prática}

Para as enfermeiras, refletir sobre a prática engloba as idéias de resgate da memória, de repensar a prática profissional e ver a si mesmas como instrumentos de transformação.

\section{Resgatando a memória}

Primeiramente ao falarem sobre o significado de desmedicalização as enfermeiras fizeram uma reflexão sobre sua prática onde utilizaram a memória para recordar suas histórias de vida:

\begin{abstract}
Durante a minha trajetória de vida eu fui me apropriando de outros conhecimentos, outras possibilidades. E aí descobri na minha família que minha bisavó era parteira tradicional, no interior e que metade da comunidade tinha nascido na mão dela. Descobri com a minha avó que todos os seus doze partos tinham sido de cócoras, em casa e com o meu avô apoiando. Ela nunca chegou a permitir que nenhum médico a visse nas partes íntimas, como ela dizia (E01).
\end{abstract}

Em outros depoimentos as enfermeiras reviveram o início de suas vidas profissionais, onde sua escolha de trabalho não era respeitada, o que gerava muita insegurança profissional:
Eu fui aprovada no concurso, fui lotada numa maternidade, o que não me agradou. Mas eu caí numa maternidade, era onde tinha vaga. Eu achava que eu ia matar todo mundo porque eu não sabia trabalhar com mulher e com criança (E06).

No exercício de reflexão sobre sua prática associaram o conhecimento adquirido através da formação acadêmica com o modelo medicalizado de assistência ao parto:

Eu venho de uma formação que era intervencionista, era com medicação sim. Eu quando trabalhava em sala de parto fazia episiotomia, anestesiava de rotina. É difícil você mudar uma cultura que você aprendeu [...] Você viveu aquilo (E07).

\section{Repensando a prática profissional}

0 contato e a interação com pessoas do movimento de humanização contribuíram para o exercício reflexivo sobre sua prática profissional:

\begin{abstract}
Através de conversas, participação em eventos, discussões com o pessoal [do movimento de humanização] eu comecei a repensar o que estava fazendo (E01).
\end{abstract}

0 contato com escolas que adotaram um projeto político pedagógico crítico-reflexivo e desmedicalizado, também colaborou para que as enfermeiras repensassem sua prática e renovassem também sua visão de mundo:

\begin{abstract}
E aí eu vim fazer o curso que deu outro nó na minha cabeça. Aprendi que enfermeira não fazia o parto, ela cuidava, e como se usa aquilo tudo, e desmedicalização e gênero e sexualidade e fisiologia [...] tudo novidade. [...] realmente foi uma mudança de mim mesma (E06).
\end{abstract}

\section{Vendo a si mesma como instrumento de transforma ação}

No processo de construção do significado da desmedicalização as participantes deste estudo, perceberam-se como agentes em potencial de mudança e, portanto capazes de realizar transformações no ambiente em que atuam influenciando inclusive outros profissionais:

\footnotetext{
Eu acredito que eu consegui mudar. Na hora [do parto] eu tentava convencer [a enfermeira]: - não vamos fazer [a episiotomia]. Eu acho que eu consegui plantar uma semente nela [...] Mostrando pra ela que o quê ela ta fazendo não é tão necessário (E03).

A gente de alguma forma mobilizou os auxiliares que trabalhavam na nossa equipe, então eu acho que isso foi um ganho porque eu tenho certeza que essas pessoas hoje agem de forma diferente (E08).
}

\section{Caracterizando a prática obstétrica hospitalar como medicalizada}

Caracterizar a prática obstétrica hospitalar como medicalizada foi possível para estas enfermeiras quando conseguiram identificar atitudes dos profissionais como 
medicalizadas, reconhecer as práticas obstétricas medicalizadas dentre aquelas usualmente realizadas em seu ambiente de trabalho, e perceber a mulher como objeto passivo da assistência.

Identificando atitudes dos profissionais de saúde como medicalizadas

Para as enfermeiras obstétricas, a construção do significado de desmedicalizar, perpassou também pela identificação, no ambiente em que estavam inseridas, de atitudes de cunho medicalizado:

$E$ até porque aquela questão [...] o médico tirou o parto da mulher, dessa ação da mulher pra um ato dele, ele faz o parto (E04).

Alguns colegas enfermeiros que entram e gritam dentro da sala de parto, ou perguntam o nome ou o sexo do bebê na hora da expulsão do bebê (E06).

O médico precisa aprender, então todos os procedimentos são válidos à medida que ele esteja aprendendo [...] a qualidade não é valorizada, a mulher não é vista de outra maneira que não a área pélvica enfim, o abdome gravídico (E08).

\section{Reconhecendo práticas medicalizadas}

Nesse caminho de caracterização da prática medicalizada, as enfermeiras reconheceram como práticas medicalizadas, a realização de procedimentos invasivos ou não, de modo rotineiro e sem critério bem definidos:

Então se coloca ocitocina, rompe bolsa né? Faz dolantina, e faz o Kristeller, e faz outras coisas né, pra fazer aquele menino sair, não é verdade? (E01).

Eles utilizam como rotina a episiotomia, eles utilizam como rotina a ocitocina (E04).

\section{Percebendo a mulher como objeto passivo da assistência}

As enfermeiras quando caracterizam o modelo medicalizado identificaram que as mulheres têm baixa autoestima, passividade e sensação de incapacidade:

A mulher não consegue ainda resgatar essa auto-estima. Ela não consegue se colocar como sujeito. Muitas vezes você dá a oportunidade a ela de escolher alguma coisa, ela fica perdida, porque ela tava acostumada o tempo inteiro a ser objeto (E01).

Às vezes a mulher vem muito submissa achando que não é capaz, achando que o processo de parir é do enfermeiro obstetra ou do médico (E04).

\section{Incomodando-se com a assistência medicalizada}

O sentimento de agressão por serem impelidas a adotarem práticas com as quais começavam a discordar, no decorrer deste processo, foi ponto marcante na mudança de sua atitude frente ao cuidado à mulher no parto.

Sentindo-se agredida com a realidade da assistência à mulher

As entrevistadas sentiram-se agredidas quando foram pressionadas para agirem de acordo com as práticas do modelo medicalizado:

A primeira coisa que me deram quando fui fazer um parto foi uma seringa com um anestésico e o bisturi. E eu olhei aquilo e pensei como é que eu vou fazer episiotomia se eu não sei e eu to vendo que não precisa? É muito difícil você fazer uma coisa que você não está aceitando. Aquilo pra mim foi meio torturante (E03).

\section{Identificando princípios da desmedicalização}

Associar a fisiologia do parto, a não intervenção desnecessária e o protagonismo da mulher com a desmedicalização, permitiu às enfermeiras obstétricas encontrarem os pilares sobre os quais se construíram o significado que norteia sua prática.

\section{Relacionando desmedicalização com a fisiologia do parto}

As enfermeiras associam a desmedicalização à valorização do fisiológico, isto é, do que é peculiar e função do corpo grávido da mulher. Apresentam em suas falas uma nova evidência que se contrapõe às verdades que não eram constatadas pelo modelo biomédico sobre a utilização de práticas intervencionistas:

\footnotetext{
Então todas essas técnicas que utilizamos ajudam pro bom andamento do trabalho de parto, durante o trabalho de parto em si. [...] de se permitir que o processo aconteça naturalmente, sem estar utilizando a episiotomia ou a ocitocina como rotina (E04).
}

Todas essas técnicas que a gente usa a gente está provando por $A+B$ que a gente consegue [...] um parto sem ocitocina externa, sem Kristeller e sem episiotomia (E03).

Relacionando desmedicalização com o não uso desnecessário de práticas intervencionistas

As enfermeiras evidenciaram no seu discurso que a desmedicalização implica na não intervenção quando esta não se faz necessária, pontuando que as intervenções só devem ser usadas quando realmente existir uma indicação apropriada para o contexto:

\footnotetext{
Então pra mim desmedicalização é isso, só usar as intervenções no momento em que realmente elas se façam necessárias (E01).

Só fiz mesmo (episiotomia), realmente quando eu achei necessário (E03).
}

\begin{tabular}{|c|c|}
\hline $31 \begin{array}{r}\text { Rev Esc Enferm USP } \\
2008 ; 42(2): 339-46 . \\
\text { www.ee.usp.br/reeuspl }\end{array}$ & $\begin{array}{l}\text { O significado de desmedicalização da assistência ao parto no hospital: } \\
\text { análise da concepção de enfermeiras obstétricas } \\
\text { Vargens OMC, Progianti JM, Silveira ACF }\end{array}$ \\
\hline
\end{tabular}


Relacionando desmedicalização com o protagonismo da mulher

As enfermeiras em sua totalidade reconheceram a muIher como protagonista do evento do parto e do nascimento. Assim, passaram a cuidar das mulheres numa perspectiva de encorajamento porque acreditam que ela sabe e pode parir:

A gente consegue mesmo mostrar pra ela que ela pode entendeu? Eu acho que mostrar que ela pode é muito importante. Ela é mulher e ela consegue. [...] A gente consegue trabalhar isso, a gente mostrando pra ela o poder que essa mulher tem. A mulher tem esse poder, não só de gerar, mas como botar o filho no mundo (E03).
Esse processo acontece pela natureza da mulher. Ela é sujeito ativo de todo o processo. [...] porque o parto não é feito pelos profissionais, é por ela (E04).

Vai porque você vai fazer tudo [...] faz ele nascer, porque você pode fazer ele nascer, eu não posso (E08).

\section{INTEGRAÇÃO E DISCUSSÃO DAS CATEGORIAS}

A integração destas categorias permitiu a identificação do processo designado construindo o significado de desmedicalização.

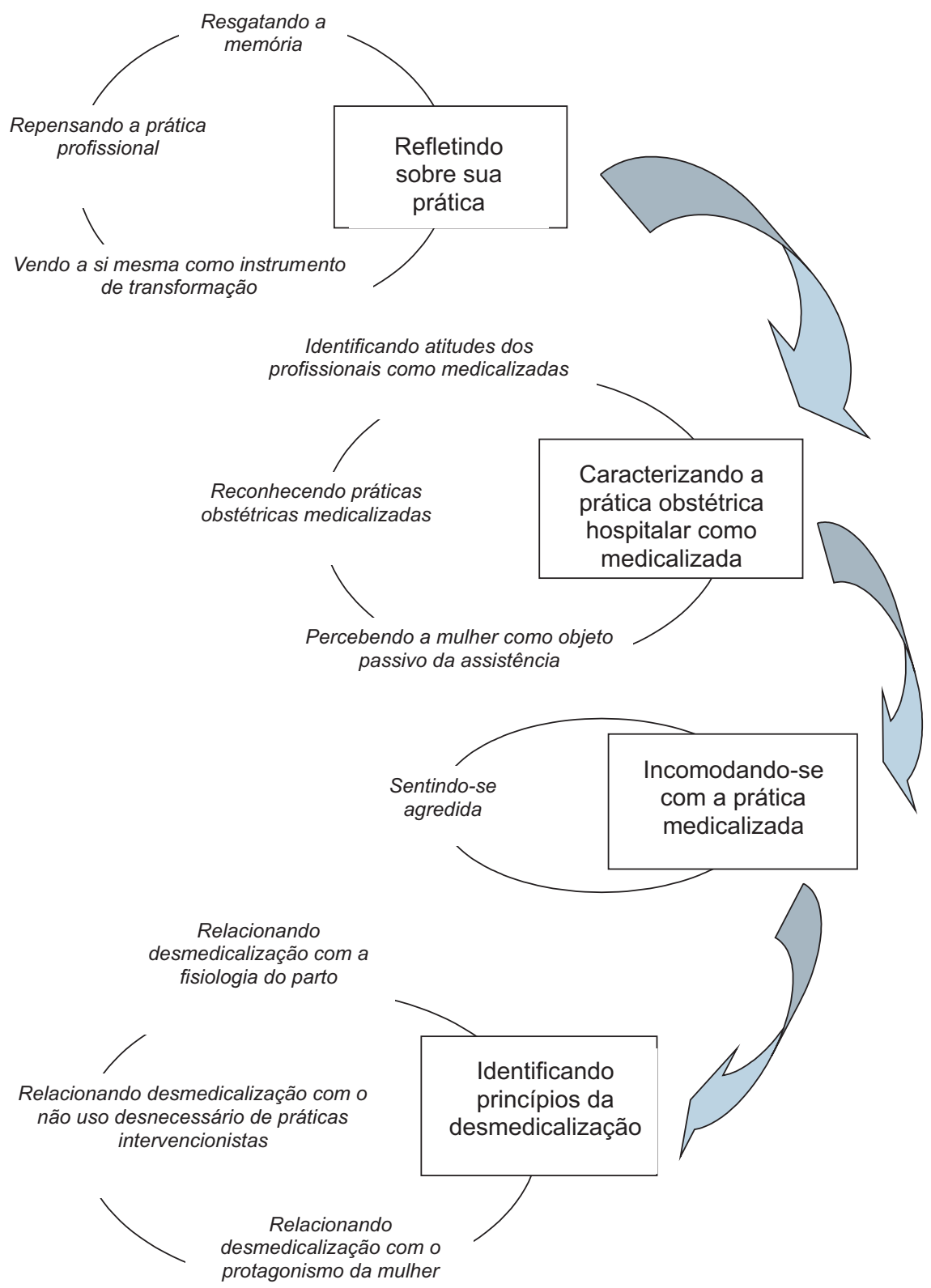

Figura 1: Representação esquemática do processo de construção do significado de desmedicalização para enfermeiras obstétricas - Rio de Janeiro - 2006 
$\mathrm{Na}$ construção do significado de desmedicalização as enfermeiras passam a refletir sobre sua própria prática. Isto inclui o Resgate da memória, o repensar a prática profissional e a visão de si mesmas como instrumentos de transformação.

Ao pensar suas memórias, o ser humano seria o idealista de sua própria história, escolhendo determinados fatos significativos em função de uma intenção global, estabelecendo entre eles ligações adequadas, de modo a conferir-Ihes coerência. Assim, são gerados sentidos a partir de uma retórica ordenadora da descontinuidade do real, tratando-se, portanto de um esforço de representação, de produção de si mesmo ${ }^{(8)}$.

Para as enfermeiras, resgatar suas memórias significou reconhecer as influências do modelo medicalizado em sua formação acadêmica. Neste sentido, a formação de enfermagem em sua grande maioria continua seguindo o modelo biomédico(9) ou modelo tecnocrático ${ }^{(10)}$ que é baseado na ciência e conduzido por instituições que valorizam o patriarcado, o tecnicismo e a supremacia da instituição sobre 0 indivíduo ${ }^{(9-10)}$.

Esse tipo de formação que fundamenta o fazer dos profissionais, caracteriza a existência de duas vertentes de profissionais na enfermagem obstétrica: os que não romperam com o modelo biomédico de assistência, e aqueles que romperam com este modelo ${ }^{(11)}$.

Neste caminhar de reflexões, as enfermeiras repensaram sua prática profissional com o intuito de trilhar um caminho de transformações. Reconheceram que foi através do contato com realidades distintas, e da interação com outras pessoas que se apropriaram de diferentes conhecimentos relacionados à saúde da mulher, em especial ao momento do parto. 0 contato com escolas que adotaram um projeto político pedagógico crítico-reflexivo e desmedicalizado, também colaborou para que as enfermeiras repensassem seus fazeres e renovassem sua visão de mundo ${ }^{(12)}$.

Nesta reflexão, as enfermeiras vêem a si mesmas como instrumento de transformação, capazes de lançar mão de estratégias para transformar 0 ambiente em que atuam ${ }^{(13)}$.

A partir de então conseguem caracterizar a prática obstétrica hospitalar como medicalizada, quando Identificam atitudes dos profissionais como medicalizadas, reconhecem práticas obstétricas medicalizadas e percebem a mulher como objeto passivo da assistência. As enfermeiras Incomodamse com esta assistência por se sentirem agredidas.

À medida que começavam a olhar a mulher de uma forma diferente, observavam que o modelo de atenção biomédica vigente não contemplava todas as necessidades da clientela. Muitas vezes, as enfermeiras perceberam-se em situações conflitantes e incômodas(14). Por isso, caracterizavam, no ambiente em que estavam inseridas, as atitudes e práticas/procedimentos como sendo de cu- nho medicalizado, e ainda observavam os impactos provenientes do modelo biomédico no comportamento das mulheres.

De certa forma, o conjunto das práticas institucionais médicas institucionalizou o paciente, submetendo-o ao saber e poder médico. Tanto o hospital quanto a prática médica cujos discursos freqüentemente destacam o bemestar do paciente, podem ser vistos como partes estratégicas do exercício da dominação e transformação da muIher em propriedade institucional no processo de parto e nascimento ${ }^{(15)}$. Isto caracteriza a cultura institucional.

Independente da cultura institucional, as pessoas costumam fazer uso dos rituais para dar a elas mesmas a sensação de ordem, estabilidade e controle. No campo da medicina, e particularmente na atenção ao parto e nascimento, onde a incerteza e o caos permeiam a prática diária, utilizar e apegar-se às rotinas com as quais esses profissionais podem demonstrar competência serve para controlar o medo e aumentar a autoconfiança sobre as situações que de forma geral são imprevisíveis ${ }^{(10)}$. Esta idéia reforça a concepção de prática obstétrica hospitalar medicalizada reconhecida pelas enfermeiras.

A consolidação da medicalização e da hospitalização provocou uma mudança no modo de pensar da sociedade brasileira. Através do uso indiscriminado da tecnologia, o parto tornou-se perigoso e distante da mulher que perdeu sua autonomia, deixando o profissional escolher 0 tipo de conduta a ser seguido ${ }^{(16)}$.

A mulher foi despida de sua individualidade, autonomia e sensualidade, através do processo de internação, caracterizado pela separação da família, remoção de roupas e objetos de cunho pessoal, ritual de limpeza como 0 enema, e a não-deambulação ${ }^{(15)}$. Assim, vive-se numa sociedade cujo modo de pensar e agir foi culturalmente construído e consolidado.

Ainda neste processo as enfermeiras obstétricas, ao relacionarem desmedicalização com a fisiologia do parto, com o não uso desnecessário de práticas intervencionistase com o protagonismo da mulher, se vêem identificando princípios da desmedicalização.

Apesar da existência de evidências científicas suficientes para que mudanças no modelo médico tradicional de assistência ao parto sejam realizadas, promover um movimento em torno da desmedicalização significa a perda de poder para os médicos e outros profissionais ${ }^{(17)}$. Isto significa dizer que abandonar rotinas que contribuem para o modo de funcionamento do hospital e, adotar outras que valorizam o acompanhamento da fisiologia do trabalho de parto, seria perder a direção e o controle do processo de parturição e modificar as referências do papel desses profissionais neste contexto da assistência.

Para as enfermeiras o respeito à fisiologia, bem como o não uso desnecessário de práticas intervencionistas 
como rotinas, constituíram princípios da desmedicalização. Isto está em consonância com o proposto por estudos recentes sobre o processo de humanização do parto ${ }^{(5,18)}$.

Além do respeito à fisiologia, o respeito à cidadania constituiu ponto fundamental na concepção de desmedicalização. As enfermeiras passaram a relacionar a desmedicalização com o entendimento da mulher como centro da atenção e, portanto, protagonista do próprio parto. Esta idéia vem sendo seguidamente pontuada por autores que tratam do assunto ${ }^{(11,19-20)}$.

\section{CONSIDERAÇÕES FINAIS}

0 estudo aponta para as diferentes dimensões que interferiram na desconstrução e renovação da visão de mundo de um grupo profissional. Os resultados nos mostraram que o significado de desmedicalização para as enfermeiras pesquisadas foi construído num processo dinâmico, sendo diretamente influenciado pela sua participação ativa no campo da parturição.

Pode-se dizer que a reflexão sobre sua vida e a caracterização da prática obstétrica hospitalar como medicalizada fizeram parte do processo mental das enfermeiras na desconstrução das habilidades adquiridas no modelo biomédico. Por outro lado, a renovação, ini- cia-se com o incomodo e com a identificação dos princípios da desmedicalização, a partir do qual foi construído o significado de desmedicalização para estas enfermeiras obstétricas.

Este significado sustenta-se em três pilares: o respeito à fisiologia, o não uso desnecessário de práticas intervencionistas e o protagonismo da mulher em seu próprio parto. Entendemos que, desta tríade de sustentação, a associação do respeito à fisiologia e o uso desnecessário de práticas intervencionistas requer ainda uma elaboração teórica mais aprofundada.

O estudo nos leva a propor que, independente da categoria profissional prestadora de serviços à cliente parturiente, questões que transcendem o corpo biológico necessitam fazer parte do planejamento da assistência e das discussões no âmbito das políticas ou dos grupos profissionais, pois são demandas significativas e que possuem repercussões para mulheres, principalmente para aquelas em trabalho de parto.

A realização deste trabalho não esgota o estudo das dimensões em torno da contribuição da enfermeira obstétrica, da desmedicalização do parto e da opção pelo modelo desmedicalizado de cuidado à mulher. Na verdade, este estudo tem a finalidade de estimular o desenvolvimento de outras pesquisas, com novos olhares e outras interpretações.

\section{REFERÊNCIAS}

1. Progianti JM, Barreira IA. Parteiras, médicos e enfermeiras: a aquisição de habilidades profissionais na assistência à parturiente (Rio de Janeiro 1934-1949). Esc Anna Nery Rev Enferm. 2001;5(3):307-14.

2. Vargens OMC, Progianti JM, Lima ML, Medina ET, Lessa $H$. Desmedicalização da assistência ao parto e ao nascimento: um desafio para a enfermagem obstétrica brasileira. Enferm Atual. 2003;3(17):12-8.

3. Castro JC. Parto humanizado na percepção dos profissionais de saúde envolvidos com a assistência ao parto [dissertação]. Ribeirão Preto: Escola de Enfermagem de Ribeirão Preto, Universidade de São Paulo; 2003.

4. Brasil. Ministério da Saúde. Secretaria de Políticas de Saúde. Parto, aborto e puerpério: assistência humanizada à mulher. Brasília; 2001.

5. Progianti JM, Vargens OMC. As enfermeiras obstétricas frente ao uso de tecnologias não invasivas de cuidado como estratégias na desmedicalização do parto. Esc Anna Nery Rev Enferm. 2004;8(2):194-7.

6. Glaser BG. Basics of grounded theory analysis. Mill Valley: Sociology Press; 1992.
7. Hutchinson S. Grounded theory: The method. In: Munhall $P_{\text {, }}$ Oiler $C$, editors. Nursing research: a qualitative perspective. Norwalk: Appleton-Century-Crofts; 1986. p. 111-30.

8. Bourdieu P. La ilusion biografica. Hist Fuente Oral. 1989; (2):27-33.

9. Pereira ALF. O parto assistido pela enfermeira na política de humanização ao parto e nascimento [dissertação]. Rio de Janeiro: Núcleo de Tecnologia Educacional para a Saúde, Universidade Federal do Rio de Janeiro; 2001.

10. Davis-Floyd R, St. John G. The tecnocratic model of medicine. New Bruswick: Rutgers University Press; 1998. From doctor to healer. The transformative journey; p. 15-48.

11. Osava RH, Tanaka ACD. Os paradigmas da enfermagem obstétrica. Rev Esc Enferm USP. 1997;31(1):96-108.

12. Vargens OM C, Progianti JM. O processo de desmedicalização da assistência à mulher no ensino de enfermagem. Rev Esc Enferm USP. 2004;38(1):46-50.

13. Progianti JM, Lopes AS, Gomes RCP. A participação da enfermeira no processo de desmedicalização do parto. Rev Enferm UERJ. 2003;11(3):271-8. 
14. Hoga LAK. Motivação de enfermeiras obstétricas para o desenvolvimento de seu trabalho em uma casa de parto. REME Rev M in Enferm. 2004;8(3):368-72.

15. Nagahama EEI, Santiago SM. A institucionalização médica do parto no Brasil. Ciênc Saúde Coletiva. 2005; 10 (3):651-7.

16. Seibert SL, Barbosa JLS, Santos JM, Vargens OMC. M edicalização X humanização: o cuidado ao parto na história. Rev Enferm UERJ. 2005;13(2):245-51.

17. Dias MAB, Domingues RM SM. Desafios na implantação de uma política de humanização da assistência hospitalar ao parto. Ciênc Saúde Coletiva. 2005;10(3):699-705.
18. Vargens OM C, Progianti JM, Araújo LM. A humanização como princípio norteador do cuidado à mulher. In: Quintella RA, Narchi NZ. Enfermagem e saúde da mulher. São Paulo: Manole; 2007. p. 277-87.

19. Diniz SG, Chacham A. Dossiê humanização do parto. São Paulo: Rede Feminista de Saúde; 2002.

20. Costa AA. Gênero, poder e empoderamento das mulheres [texto na Internet]. Brasília: AGENDE, 2006 [citado 2007 fev. 27]. Disponível em: http://www.agende.org.br/ docs/File/dados_pesquisas/feminismoEmpodera men to $\% 20-\% 20$ Ana $\% 20$ Alice.pdf. 